\title{
Original Article \\ HEALTH RELATED QUALITY OF LIFE OF THYROID CANCER PATIENTS
}

\author{
AKM Farhad Hossain', Md. Ziaul Islam ${ }^{2}$, Sayada Fatema Khatun ${ }^{3}$
}

\begin{abstract}
Background: Having the longevity of thyroid cancer patients, any impairment in health-related quality of life (HRQOL) during the follow-up period is of great importance.

Objective: The study was conducted to determine the health related quality of life of thyroid cancer patients.

Material and methods: This cross sectional study was conducted among 246thyroid cancer patients. Data were collected by face-to-face interview and reviewing medical records with semi-structured questionnaire and checklist with validated scale. The subjects were purposively selected following specific selection criteria and maintaining ethical issues.
\end{abstract}

Place and period of study: The study was conducted during the period from July 2018-June 2019 in two tertiary hospitals of Dhaka city: Bangabandhu Sheikh Mujib Medical University and Dhaka Medical College Hospital, Dhaka.

Results: This study revealed that majority (74.4\%) of respondents was female, married (72\%), housewife (61.4\%), rural respondent $(41.1 \%)$ and had primary education $(69 \%)$. Mean $( \pm$ SD) age of the respondent was 37.85( \pm 12.20$)$ years (range 14-70 years) and mean ( \pm SD) monthly family income was Tk.17681( \pm 10602$)$. Out of 246 cases, 204 $(82.9 \%)$ was papillary and $42(17.1 \%)$ was follicular carcinoma. Main presenting features were neck swelling $(91.5 \%)$, swollen lymph node (41.9\%), dysphonia (57.3\%) and dysphagia (35.4\%). Mean ( \pm SD) of total HRQOL score was $73.7 \pm 8.39$. HRQOL score of students and higher educated patients were better among the respective groups ( $\mathrm{p}<.001$ ). The study showed the association of HRQOL with clinical condition of thyroid cancer patients $(\mathrm{R} 2=.025)$. HRQOL revealed the strong prediction with education $(\beta=-0.888, p<.05)$, family income $(\beta=0.05$, $\mathrm{p}<.05)$, marital status $(\beta=-0.1 .384, \mathrm{p}<.05)$, clinical condition $(\beta=-0.522, \mathrm{p}<.05)$ and perceived stress $(\beta=-0.632$, $\mathrm{p}<.001)$.

Conclusion: The overall HRQOL score was considerably good in this study. Timely detection, regular motivation and attending clinical condition may significantly improve the HRQOL of thyroid cancer patients

JOPSOM 2019; 38(2): 1-8

Key words: HRQOL, Thyroid Cancer Patient, Clinical Attributes.

\footnotetext{
1. Commanding Officer Cantonment Medical Hospital Ramu, Cox's Bazar.

2. Professor and Head Department of Community Medicine National Institute Preventive and Social Medicine (NIPSOM), Mohakhali, Dhaka-1212.

3. Consultant Gyanecologist Bangabandhu Sheikh Mujib Medical University (BSMMU), Dhaka-1000.
}

\section{Correspondence:}

AKM Farhad Hossain

Cell phone: +8801769050760,

E-mail: farhad100884@gmail.com

\section{INTRODUCTION}

Thyroid cancer is accounting for $92 \%$ of all endocrine malignancies ${ }^{1}$ Incidence continues to rise worldwide due to increased diagnostic facilities and surveillance. ${ }^{2}$ Annually it varies from 0.5 to 10 per 100,000 population. The survival rate of people with thyroid cancer is $98 \%$ for 5 years. $^{3}$ In USA, about17,000 new cases of thyroid cancer are diagnosed annually and deaths is about $1300 .{ }^{4}$ It is the fifth most common cancer in women in USA. ${ }^{5}$ Thyroid cancer occurs in the 3 rd and 4th decade of life. $^{4}$

Survival is the main outcome measure in oncology patients but recently it has been recognized that the diagnosis and management have a major effect on HRQOL of a cancer patient. The aim of cancer 
treatment became not only to increase survival but also to preserve HRQOL and measuring these changes has been considered to be of paramount importance. ${ }^{6}$

The prevalence of thyroid cancer is increasing as a consequence of rising incidence, young age at diagnosis and excellent survival. Majority of the patients will live for many years with the consequences of treatment and follow-up, so their long-term quality of life becomes of great importance. After surgery, most of the patients will receive long-term thyroid hormones to decrease the risk of recurrence. Therefore, HRQOL might be affected by side-effects from thyroid hormones. ${ }^{7}$ Health related quality of life refers to a multidimensional concept that encompasses perception of negative and positive aspects of physical, emotional, social, and cognitive functions, which could be affected by the disease or its treatment. $^{8}$

Until recently, measurement of treatment efficacy depends on the overall survival in evaluating the treatment of malignant tumors. Large numbers of cancer patients are now surviving for many years with improved early detection and treatment and has heightened interest in studying long-term effects of cancer on HRQOL. ${ }^{9}$

Incidence of thyroid cancer in Bangladesh is not known exactly but in one study at INM \& thyroid clinic in BSMMU Dhaka reviewed 2629 thyroid patients from January 1994 to June 1995, and found prevalence of thyroid carcinoma $2.58 \% .{ }^{10}$

Assessment of HRQOL and its contributing factors are important in the management of thyroid cancer patients because early identification may help to implement appropriate intervention to those with poor HRQOL. In Bangladesh no significant study was done about HRQOL of thyroid cancer patients. This study was conducted to determine the HRQOL of thyroid cancer patients for contributing profound academic and policy implications in detection of the magnitude of problem and to take necessary steps to provide economic and infrastructural support to reduce the burden of the disease.

\section{MATERIALS AND METHODS}

A cross sectional study was explored among 246

purposively selected thyroid cancer patients who were diagnosed by expert Oncologist with considering the histopathological report and were being followed in Institute of Nuclear Medicine and Allied Science of Bangabandhu Sheikh Mujib Medical University (BSMMU) and Dhaka Medical College Hospital (DMCH) from 01 July 2018 to 30 June 2019. FACT-G (version 4), 1127-item compilation of general questions was used to determine HRQOL of thyroid cancer patients in which the scored items employed a Likert-type format ( 0 to 4 "not at all to very much"). FACT-G scored was calculated by summing the individual scale scores and the total score was0-108, with higher scores indicating better quality of life. There were 7 items for assessing the clinical attributes of thyroid cancer patients and this assessment was done by employing a Likert-type format (not at all, a little, quite a bit, very much). After pretesting, the questionnaire was finalized and used for data collection. Informed written consent of each respondent was obtained before data collection. After explaining the purpose of the study, data were collected by face to face interview using a semistructured questionnaire and checklist through reviewing medical records of the respective participants. Collected Data was analyzed with the help of Statistical Package of Social Science (SPSS) version 23. Data were presented in frequency tables and diagram to identify the distribution and clinical characteristics of the disease.

\section{RESULTS}

Out of total 246 thyroid cancer patients, majority $(50.4 \%)$ were $30-49$ years old with a range of 14-70 years and the mean $( \pm$ SD) age was $37.85 \pm 12.20$ years. Most of the thyroid cancer patients i.e. $74.4 \%$ were female and male female ratio was $1: 3$. Study revealed that $72 \%$ respondent was married, $61.4 \%$ were house wife, and $41.1 \%$ were from rural area. Around $28 \%$ had primary education while $20.7 \%$ were illiterate and average monthly family income was Tk. $17681 \pm 10602$ (Table 1).

Table 1: Distribution of thyroid cancer by socio-demographic character $(n=246)$

\begin{tabular}{|l|l|}
\hline Attributes & Findings \\
\hline Age (Years) & 14-19: 63(25.6\%), 20-29: 54(22\%), 30-49: 124(50.4), 50-70: 55(22.4\%) \\
\hline Gender & Male: 63(25.6\%), Female: 183(74.4\%) \\
\hline
\end{tabular}


Table 1: Distribution of thyroid cancer by socio-demographic character $(n=246)$

\begin{tabular}{|l|l|}
\hline Attributes & Findings \\
\hline Marital status & Married: 177(72\%\%), Unmarried: 32(13\%) Widow:27(11\%) Divoce:10(4.1\%) \\
\hline Education & $\begin{array}{l}\text { Illiterate: 51(20.7\%), Primary: 69(28\%), Secondary: 27(11\%), SSC: 38(15.4\%) } \\
\text { HSC: } 25(10.2 \%), \text { Graduate: 21(8.5\%), Masters: 15(6.1\%), Illiterate: 51(20.7\%) }\end{array}$ \\
\hline Occupation & $\begin{array}{l}\text { Students: 14(5.7\%), Unemployed: 11(4.5\%) Farmer: 7(2.8\%), Business: 19(7.7\%) } \\
\text { Service holder: 35(14.2\%) Day laborer: 5(2.0\%) Retired: 4(1.6\%) }\end{array}$ \\
\hline Monthly family income & $\begin{array}{l}\text { Tk. 5000-10,000: 89(36.2\%), Tk.10001-20000: 109(44.3\%), Tk. 20001-30000: } \\
\pm 10602\end{array}$ \\
\hline Place of residence & Rural: 101(41.1\%) Urban: 72(29.3\%) Peri-urban: 73(29.7\%) \\
\hline
\end{tabular}

The most frequent thyroid cancer found in this study was papillary carcinoma $204(82.9 \%)$ followed by

follicular carcinoma $42(17.1 \%)$ (Figure 1).

Figure 1: Distribution of patients by type of thyroid cancer $(n=246)$

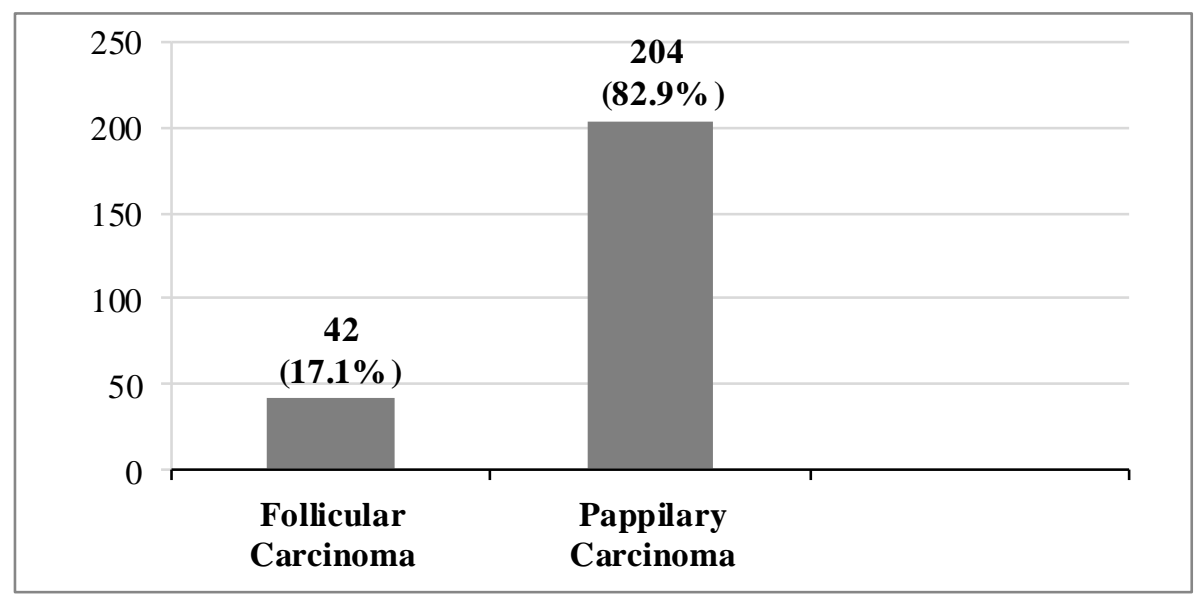

Most common presentation of study participants was visible neck swelling in 225 (91.5\%), swollen lymph node in $103(41.9 \%)$, pain in $90(36.6 \%)$, difficulties in swallowing in 87 (35.4\%), Hoarseness of voice in
141 (57.3\%), cough along with swelling in $47(19.1 \%)$ and difficulties in breathing in $13(5.3 \%)$ of the patients (Table 2). 
Table 2: Distribution of thyroid cancer patients by clinical attributes $(n=246)$

\begin{tabular}{|c|c|c|c|c|c|}
\hline Attributes & $\begin{array}{c}\text { Not at all } \\
\text { f }(\%)\end{array}$ & $\begin{array}{c}\text { A little } \\
\text { f (\%) }\end{array}$ & $\begin{array}{c}\text { Quite a bit } \\
\text { f (\%) }\end{array}$ & $\begin{array}{c}\text { Very much } \\
\text { f }(\%)\end{array}$ & $\begin{array}{l}\text { Total } \\
\text { f }(\%)\end{array}$ \\
\hline Visible lump in neck & $21(8.5 \%)$ & $146(59.3)$ & $68(27.6)$ & $11(4.5)$ & 100 \\
\hline Swollen lymph node & $143(58.1)$ & $98(39.8)$ & $5(2.0)$ & $0(00)$ & 100 \\
\hline Pain due to lump & $156(63.4)$ & $82(33.3)$ & $8(3.3)$ & $0(00)$ & 100 \\
\hline Difficulties in swallowing & $159(64.6)$ & $77(31.3)$ & $10(4.1)$ & $0(00)$ & 100 \\
\hline Hoarseness of voice & $105(42.7)$ & $98(39.8)$ & $43(17.5)$ & $0(00)$ & 100 \\
\hline Cough along with swelling & $199(80.9)$ & $47(19.1)$ & $0(00)$ & $0(00)$ & 100 \\
\hline Breathlessness due to lump & $233(94.7)$ & $13(5.3)$ & $0(00)$ & $0(00)$ & 100 \\
\hline
\end{tabular}

The overall score of total HRQOL and its domains were presented in (Table 3). Among the respondents, mean \pm SD of total HRQOL score was $(73.7 \pm 8.39)$. Among domains, mean \pm SD score was highest in
Physical Well-Being (PWB) (22.07 \pm 3.87) and lowest in Functional Well-Being (FWB) $18.65 \pm$ 4.17(Table 3).

Table 3: Distribution of patients by mean score of HRQOL and domain $(\mathrm{n}=246)$

\begin{tabular}{|c|c|c|c|c|}
\hline Attributes & Maximum Score & Mean \pm SD & Median & Range \\
\hline Physical Well-Being (PWB) & 28 & $22.07 \pm 3.87$ & 22 & $12-28$ \\
\hline Social Well-Being (SWB) & 28 & $19.26 \pm 3.62$ & 20 & $10-28$ \\
\hline Emotional Well-Being (EWB) & 24 & $26.5 \pm 2.97$ & 19 & $10-24$ \\
\hline Functional Well-Being (FWB) & 28 & $18.65 \pm 4.17$ & 14 & $5-28$ \\
\hline Total HRQOL & 108 & $73.7 \pm 8.39$ & 74 & $49-102$ \\
\hline
\end{tabular}


Mean \pm SD of the HRQOL score of students

$77.86 \pm 8.484$ and graduates $76.90 \pm 8.300$ which were highest among the respective groups and were statistically significant ( $<$.001) (Table 4).

Table 4: Comparison of mean score of HRQOL by selected socio-demographic characters $(n=246)$

\begin{tabular}{|c|c|c|c|}
\hline Attributes & $n=246$ & $\begin{array}{c}\text { Mean } \pm \text { SD of } \\
\text { HRQOL }\end{array}$ & Significance \\
\hline \multicolumn{3}{|c|}{ Occupation } & \multirow{9}{*}{$\begin{array}{c}\text { (Test Value }=.023) \\
\mathrm{F}=2.370 \\
\mathrm{df}=7 \\
\mathrm{P}<.05\end{array}$} \\
\hline Student & 14 & $77.86 \pm 8.484$ & \\
\hline Service & 35 & $72.11 \pm 9.508$ & \\
\hline Retired & 4 & $69.00 \pm 4.243$ & \\
\hline Business & 19 & $77.68 \pm 7.754$ & \\
\hline Farming & 7 & $68.29 \pm 5.908$ & \\
\hline Housewife & 151 & $73.65 \pm 8.358$ & \\
\hline Unemployed & 11 & $75.18 \pm 4.708$ & \\
\hline Day labor & 5 & $67.80 \pm 4.025$ & \\
\hline \multicolumn{3}{|c|}{ Education } & \multirow{8}{*}{$\begin{array}{c}\text { (Test Value }=.027 \\
\begin{array}{c}\mathrm{F}=2.418 \\
\mathrm{df}=6 \\
\mathrm{P}<.05\end{array}\end{array}$} \\
\hline Illiterate & 51 & $70.69 \pm 6.386$ & \\
\hline Primary & 69 & $73.25 \pm 8.806$ & \\
\hline Secondary & 27 & $74.81 \pm 8.298$ & \\
\hline SSC (Pass) & 38 & $73.66 \pm 9.356$ & \\
\hline HSC (Pass) & 25 & $76.88 \pm 8.217$ & \\
\hline Graduate & 21 & $76.90 \pm 8.300$ & \\
\hline Masters & 15 & $74.40 \pm 8.096$ & \\
\hline
\end{tabular}

The study showed the association of HRQOL with

clinical condition of thyroid cancer patients $(\mathrm{R} 2=.025)$ (Figure 2).

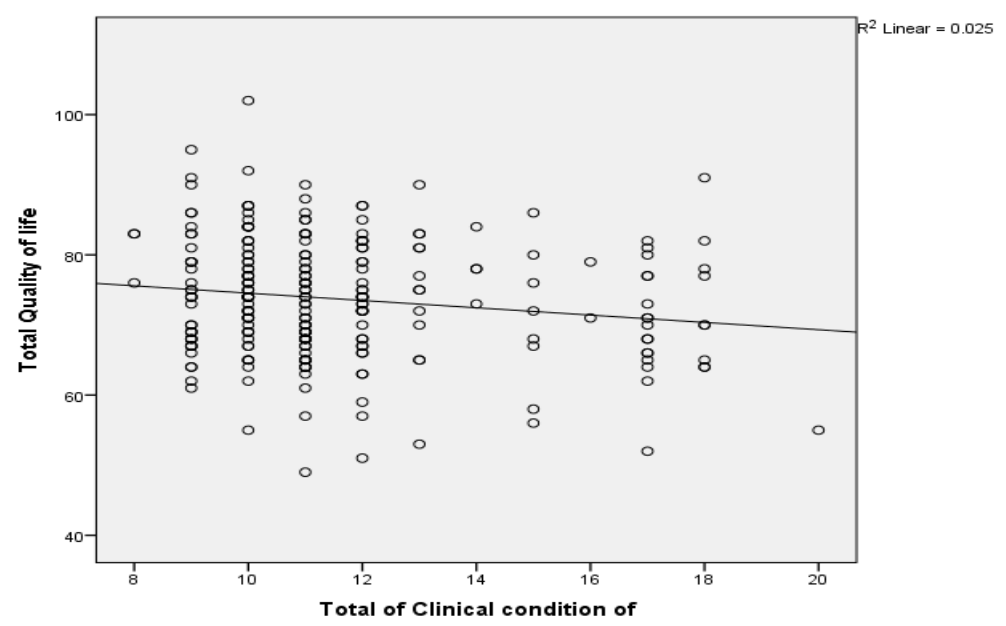

Figure 2: Linear regression analyses between clinical condition score and HRQOL score $(\mathbf{n}=\mathbf{2 4 6})$ 
Table 5: Multiple regression analysis of predictors of HRQOL among thyroid cancer patients

\begin{tabular}{|c|c|c|c|c|c|c|}
\hline Predictor & $\mathbf{B}$ & $\mathbf{S E}$ & $\mathbf{r}$ & $\mathbf{R}$ & $\mathbf{R}^{\mathbf{2}}$ & Significance \\
\hline Perceived stress & -.632 & .124 & -.310 & .093 & $9.3 \%$ & $\begin{array}{c}\text { Test results }=.000 \\
\mathrm{p}<.001\end{array}$ \\
\hline Clinical Condition & -.522 & .209 & -.158 & .021 & $2.1 \%$ & $\begin{array}{c}\text { Test results }=.013 \\
\mathrm{p}<.05\end{array}$ \\
\hline Family Income & .000 & .000 & .149 & .018 & $1.8 \%$ & $\begin{array}{c}\text { Test results }=.019 \\
\mathrm{p}<.05\end{array}$ \\
\hline Marital Status & -1.384 & .629 & .140 & .015 & $1.5 \%$ & $\begin{array}{c}\text { Test results }=.029 \\
\mathrm{p}<.05\end{array}$ \\
\hline Education & .888 & .286 & .195 & .038 & $3.8 \%$ & $\begin{array}{c}\text { Test results }=.002 \\
\mathrm{p}<.05\end{array}$ \\
\hline
\end{tabular}

The significant factors influencing health related quality of life of thyroid cancer were education $(\beta=-$ $0.888, \mathrm{p}<.05)$, family income $(\beta=0.05, \mathrm{p}<.05)$, marital status $(\beta=-0.1 .384, \quad \mathrm{p}<.05)$, clinical condition $(\beta=$ $0.522, \mathrm{p}<.05)$ and perceived $\operatorname{stress}(\beta=-0.632, \mathrm{p}<.001)$ (Table 5).

\section{DISCUSSION}

This cross-sectional study was conducted among 246 thyroid cancer patients. The mean \pm SD age of participants was $37.85 \pm 12.20$ years and the highest frequency 124 (50.4\%) was in between 30-49 years with a range of 14-70 years which is similar to other studies (Table 1). ${ }^{12,13}$ Male were $63(25.6 \%$ ) and female were $183(74.4 \%)$ and male female ratio was 1:3(Table1). Females are more in numbers probably due to the roles of hormones. Findings are consistent with the study by Haque GHMS $^{14}$ may be due to same geographical location.

Out of all respondents, $20.7 \%$ were illiterate, and $28 \%$ had primary level education. Present data supports the national statistics where literacy rate was shown as $72.8 \% \quad .{ }^{18} \mathrm{In}$ respect of occupation, respondent were mostly $(61.4 \%)$ house wife. Among the respondents, $72 \%$ were married, $13 \%$ were unmarried, and others were in different strata (Table 1). A study Tagayet $\mathrm{al}^{15}$ showed the similar results with this study. According to the Bangladesh demographic and health service data, the usual age at marriage for male is 23.8 years and female is 18.5 years. ${ }^{16}$

Among the respondents, majority i.e. $44.3 \%$ had monthly family income Tk. 10001-20000.The mean $( \pm \mathrm{SD})$ of monthly family income was Tk. 17681 \pm 10602 (Table 1). Household income per month is 15,945.00 BDT which was reported to CEIC- a global data base organization by Bangladesh Bureau of Statistic. ${ }^{17}$

Off the all, majority i.e. $41.1 \%$ were from rural followed by $29.3 \%$ were urban and $29.7 \%$ from periurban areas. According to demographic and health service profile, the percentage of urban population is $35.8 \%$ (Table 1). ${ }^{18}$

This study revealed that most $(82.9 \%)$ of the respondents had papillary carcinoma and $17.1 \%$ had follicular carcinoma (Figure 1). The similar result was found in Merchant ${ }^{19}$ where papillary carcinoma was $80 \%$ and follicular carcinoma was $10 \%$. This similarity was probably due to study design (Figure 1).

Regarding presenting complaints, visible lump in the neck were $(92 \%)$ (Table 2) which showed the similar result in Pramod. ${ }^{20}$ This similarity was probably due to the food habit, socio- economic and environmental condition of this sub continent (Table 2). Lymph node swelling of the respondent was $(41.8 \%)$ which revealed the similar results in kannan ${ }^{21}$ (Table 2). Majority $(63.4 \%)$ of the respondents did not complain of pain due to lump which was not similar in Haque. ${ }^{22}$ Maximum $(64.6 \%)$ of the respondents had complained of difficulties in swallowing due to lump (Table 2). This did not correlate with the study Merchant $^{23}$ where it shown $16.4 \%$ of sufferings probably due to dissimilarity of study design. Most of the respondents $(57.3 \%)$ complained of hoarseness of voice in this study (Table 2). Study findings disagree with Merchant23 which showed $20 \%$ of sufferings. Respondents $(5.3 \%)$ did not complain of difficulties 
in breathing which were similar to Chidambaram ${ }^{24}$ (Table 2). This similarity was probably due to the same characteristics in geographical location of this sub continent.

Among the respondents, mean \pm SD of total HRQOL score was $(73.7 \pm 8.39)$. Among domains, mean $\pm \mathrm{SD}$ score was highest in Physical Well-Being (PWB) $(22.07 \pm 3.87)$ and lowest in Functional Well-Being (FWB) $18.65 \pm 4.17$ (Table 3). cMean score of PWB and SWB were higher among the other domain which altogether may be the fact that people got much information about the disease process and its consequences and took the medical support to cure them and to maintain a healthy life. In the present study, student and graduate personal tended to have higher HRQOL scores which depicted the similar result by Rukshani ${ }^{25}$ due to higher awareness of disease conditions, side effects of drugs and treatments (Table 4).

The study showed the association of HRQOL with clinical condition of thyroid cancer patients $(\mathrm{R} 2=.025)$ (Figure 2). Selected variables income, marital status, education, clinical condition and perceived stress emerged as strongest predictor for determinants of HRQOL in multiple regression analysis (Table 5). All had negative influence on HRQOL except education which was positive influence on HRQOL. In a study, Lee ${ }^{25}$ observed marital status, education; financial status had impact on HRQOL. Although this study was performed with small sample size in two tertiary level hospitals but still it provides a base for the future study with large sample size involving wider area representing demographics of the country.

\section{CONCLUSION}

HRQOL of thyroid cancer patient's specially physical and social well-being were better in this study and student and graduate personal tended to have the higher HRQOL scores. The study showed the association of HRQOL with clinical condition of thyroid cancer patients. HRQOL had emerged strong prediction with income, marital status, education, clinical condition and perceived stress of thyroid cancer patients. Regular motivation, educational awareness and timely clinical intervention may further improve the quality of life of thyroid cancer patients.

\section{REFERENCES}

1. Niazi S, Arshad M, Muneer M. A histopathological audit of thyroid surgical specimens. Ann King Edward Med Uni. 2007; Vol. 13:pp.51-6.
2. Vecchia C La, Malvezzi M, Bosetti C, Garavello W, Bertuccio P, Levi $F$ et al. Thyroid cancer mortality and incidence: A global overview. Int $\mathrm{J}$ Cancer. 2015:Vol.136, pp.2187-2195. https://doi.org/10.1002/ijc.29251 PMid: 25284703.

3. American Society of Clinical Oncology [ASCO], 2012; http://www.cancer.net).

4. Islam N, Shahpurwala MM, Siddiqui BK, Khan JA. Static pulmonary nodules from thyroid malignancy.J Coll Physicians Surg Pak.

5. American Cancer Society. Cancer facts \& figures, 2015. Atlanta: American Cancer Society, 2015

6. Tan LGLNanLThumbooJSundramFTan LKS Health-related quality of life in thyroid cancer survivors. Laryngoscope $2007 ; 117$ (3) 507- 510

7. Hedman C. Quality of life in patients with thyroid cancer. Instförmolekylärmedicinochkirurgi/Dept of Molecular Medicine and Surgery; 2017 Nov 2.

8. CrevennaRZettinigGKeilani $M$ et al. Quality of life in patients with non-metastatic differentiated thyroid cancer under thyroxine supplementation therapy. Support Care Cancer 2003;11 (9) 597603PubMedGoogle Scholar

9. American Society of Clinical Oncology1996Outcomes of cancer treatment for technology assessment and cancer treatment guidelinesJClin Oncol.1467167

10. Alam, M.N. Haq, S.A. Ansari, M.A.J. Karim, M.A. Das, K.K. and Baral, P.K.(1995). Spectrum of thyroid disorders in IPGMR, Dhaka.Bangladesh $\mathbf{J}$ Medicine, Vol.6, pp.53-58.

11. Brucker PS, Yost K, Cashy J, Webster K, Cella D. General population and cancer patient norms for the Functional Assessment of Cancer Therapy-General (FACT-G). Evaluation \& the health professions. 2005 Jun;28(2):192-211

12. RazaviRatki SK, Fallahi B, Namiranian N, Emami-Ardekani A, Saghari M, Mirabzadeh A, et al., Factors affecting the quality of life of welldifferentiated thyroid carcinoma patients: A crosssectional study on 435 Iranian patients. Iranian Journal of Nuclear Medicine.2016 Jul 1; Vol.24, No.2, pp.92-98.

13. Alauddin M, Joarder AH. Management of thyroid carcinoma-an experience in Bangladesh. Indian Journal of Otolaryngology and Head and Neck Surgery.2004 Jul 1; Vol.56, No.3, pp.201-205.

14. Haque GS, Farid N, Islam SS. Incidence of Complications of Thyroid Surgery. Medicine Today.2016; Vol.28, No.2, pp.62-65. 
15. Tagay S, Herpertz S, Langkafel M, Erim Y, Freudenberg L, Schopper N, et al.,Health-related quality of life, anxiety and depression in thyroid cancer patients under short-term hypothyroidism and TSH-suppressive levothyroxine treatment. European journal of endocrinology.2005 Dec 1; Vol.153, No.6, pp.755-763.

16. Bangladesh Demographic And Health Survey 2014, national institute of population research and training ministry of health and family welfare Dhaka, Bangladesh. Mitra and Associates Dhaka, Bangladesh. March 2016.

17.CEIC Data (2016). Bangladesh house hold income and expenditure survey. [Online]. Availableat:http://www.ceicdata.com/en/Bangladesh/ householdincome[Accessed 1 Feb.2018] Bangladesh Bureau of Statistics. (2015). Population Census 2011: National Report Provissional:Dhaka:Ministry of Planning,Bangladesh,Vol.12,No,4,PP,36-

40.Available at www.bbs.bd [accessed on 10 OCT.2015]

18. Bangladesh Demographic And Health Survey 2014, national institute of population research and training ministry of health and family welfare Dhaka, Bangladesh. Mitra and Associates Dhaka, Bangladesh.March 2016.

19. Merchant D. Demographic review, clinical and histological presentation of patients with primary thyroid carcinoma presenting at tertiary care hospital. The Health.2012; Vol.3, No.1, pp.7-9.

20. Pramod, S. Clinicopathological Study And Management of Carcinoma Thyroid. Dissertation.pp.81.India

21. Kannan RR. Thyroid Cancer - Indian Institutional experience. Saroj K. Mishra. Eds. Monograph on thyroid cancer. Madras. 1997; pp. 153-5.

22. Haque, G.S. Farid, N. and Islam, S.S. (2016). Incidence of Complications of Thyroid Surgery.Medicine Today, Vol.28, No.2, pp.62-65.

23. Chidambaram, S. Sankaran, M. Palanisamy, J. Maruthupandian, A. (2018).Clinical Presentation of Thyroid Carcinoma-A Retrospective Study IOSR Journal of Dental and Medical Sciences.Vol. 17, No. 4, Ver. 16 (April. 2018), pp. 18-22.

24. Rukshani D, Kahandawala P, Jayawardana K, Karunarathne D, Galgamuwa LS, Kumara C, Gamage C. Factors associated with quality of life among cancer patients in Sri Lanka. International Journal of Community Medicine and Public Health. 2018 Jun 22; 5(7):2705-13.

25.Lee JI, Kim SH, Tan AH, Kim HK, Jang HW, Hur KY, Kim JH, Kim KW, Chung JH, Kim SW. Decreased health-related quality of life in diseasefree survivors of differentiated thyroid cancer in Korea.Health and quality of life outcomes. 2010 Dec; 8(1):101. 